\title{
Kinerja Aktivasi dan Impregnasi Zeolit Alam sebagai Adsorben
}

\section{Performance of Activation and Impregnation of Natural Zeolite as Adsorbent}

\author{
Charissa Dini Sofith*, Sri Rahmadaniati Effendi, Fatimah \\ Departemen Teknik Kimia, Fakultas Teknik, Universitas Sumatera Utara \\ Jalan Almamater Kampus USU, Medan, 20155, Indonesia \\ *Email : sofithdinicharissa@gmail.com
}

\begin{abstract}
Abstrak
Kinerja zeolit alam dapat ditingkatkan melalui proses aktivasi dan impregnasi. Pada penelitian ini telah dilakukan proses aktivasi zeolit alam dengan menggunakan $\mathrm{HCl}$ dan impregnasi dengan $\mathrm{Mg}^{2+}$. Proses aktivasi dilakukan selama 30 menit dengan larutan $\mathrm{HCl}$ 0,5 $\mathrm{M}$ dan impregnasi $\mathrm{MgCl}_{2} .6 \mathrm{H}_{2} \mathrm{O} 2,5 \mathrm{M}$ selama 2 jam. Zeolit alam yang telah diaktivasi dan impregnasi kemudian dianalisis Scanning Electron Microscope-Energy Dispersive Spectrofotometer (SEM-EDS). Hasil karakteristik profil permukaan zeolit teraktivasi dan terimpregnasi menggunakan SEM-EDS menununjukkan terdapat perubahan morfologi dan gugus fungsinya. Kemudian, zeolit teraktivasi dan terimpregnasi digunakan untuk menjerap amonia pada variasi waktu kontak 5 menit, 10 menit, 15 menit, 20 menit, 25 menit, 30 menit, 35 menit, 40 menit dan 45 menit. Diperoleh titik kesetimbangan pada waktu kontak 25 menit dengan kapasitas adsorpsi 30,441 mg/g serta efisiensi penyerapan $85,2352 \%$. Dosis adsorben divariasikan dengan ukuran $0,01 \% ; 0,03 \% ; 0,05 \% ; 0,07 \%$; $0,09 \% ; 0,00,11 \%$ dan $0,13 \% \mathrm{~m} / \mathrm{v}$. Konsentrasi amonia yang terjerap dilakukan menggunakan Spektrometer Uv-Vis. Efisiensi penjerapan amonia terbaik yaitu 90,106\% dan perlakuan impregnasi adsorben.
\end{abstract}

Kata kunci: adsorpsi, aktivasi, amonia, impregnasi, zeolit

\begin{abstract}
Performance of natural zeolites can be improved through the process of activation and impregnation. Activation process using $\mathrm{HCl}$ and impregnation with $\mathrm{Mg}^{2+}$ have carried out in this study. The activation process was performed out for 30 minutes with a $0.5 \mathrm{M} \mathrm{HCl}$ solution and impregnation of $\mathrm{MgCl}_{2} .6 \mathrm{H}_{2} \mathrm{O} 2.5 \mathrm{M}$ for 2 hours. Natural zeolites which have been activated and impregnated are then analyzed by the Scanning Electron Microscope-Energy Dispersive Spectrophotometer (SEM-EDS). The results of zeolite surface profile characteristics activated and impregnated using SEM-EDS showed that there were changes in morphology and functional groups. Then, activated and impregnated zeolites were used to absorb ammonia at various contact times of 5 minutes, 10 minutes, 15 minutes, 20 minutes, 25 minutes, 30 minutes, 35 minutes, 40 minutes and 45 minutes. The equilibrium point was obtained at 25 minutes contact time with adsorption capacity of $30.444 \mathrm{mg} / \mathrm{g}$ and absorption efficiency of $85.2352 \%$. The dosage of adsorbent varied with $0.01 \%$ size; $0.03 \% ; 0.05 \% ; 0.07 \% ; 0.09 \% ; 0.11 \%, 0.13 \% \mathrm{~m} / \mathrm{v}$. The concentration of ammonia absorbed was performed out using an Uv-Vis Spectrophotometer. The best efficiency of ammonia absorption is $90.106 \%$ with particle size 110-120 mesh, adsorbent dose $0.09 \%$ and adsorbent impregnation treatment.
\end{abstract}

Keywords: activation, adsorption, ammonia, impregnation, zeolites 


\section{Pendahuluan}

Senyawa amonia merupakan salah satu komponen pencemar lingkungan. Amonia berada dalam bentuk senyawaan bebas berupa gas $\mathrm{NH}_{3}$ atau terlarut dalam air sebagai larutan amonium hidroksida $\left(\mathrm{NH}_{4} \mathrm{OH}\right)$ [1]. Resiko terbesar pada manusia saat menghirup uap amonia dapat mengakibatkan iritasi pada kulit, mata dan saluran pernafasan [2]. Untuk mengatasi limbah tersebut agar aman dibuang ke lingkungan diperlukan suatu pengolahan limbah cair, agar dapat mengurangi kadar zat berbahaya yang masuk ke dalam badan air [3]. Pengurangan kadar zat-zat berbahaya seperti amonia dapat dilakukan dengan menggunakan adsorben. Berbagai metode telah banyak dilakukan untuk menghilangkan amonia dengan cara adsorpsi menggunakan bahan adsorben karbon aktif, molekuler sieves, alumunium aktif, atau zeolit [4]. Terdapat banyak jenis zeolit alam yang teridentifikasi di dunia, terutama di Indonesia. Hal ini dikarenakan sebagian besar wilayah Indonesia terdiri dari batuan gunung api yang merupakan sumber mineral zeolit, namun pemanfaatan zeolit belum optimal, padahal dalam kenyataannya zeolit merupakan sumber daya alam yang multiguna [5]. Kinerja zeolit alam dapat ditingkatkan melalui proses aktivasi dan impregnasi.

Zeolit memiliki bentuk kristal yang sangat teratur dengan rongga yang saling berhubungan ke segala arah [6] yang menyebabkan struktur berpori pada zeolit cukup luas sehingga sangat baik digunakan sebagai adsorben. Zeolit alam yang digunakan pada penelitian ini berasal dari Kabupaten Sukabumi, Provinsi Jawa Barat. Beberapa penelitian sebelumnya telah menggunakan zeolit sebagai adsorben dan nilai efisiensi penjerapan nya tinggi yaitu 99,7\%[7] serta impregnasi zeolit alam menggunakan $\mathrm{MgCl}_{2}$ terjadi pertambahan massa $\mathrm{Mg}$ sebesar 4,73\% [8] dan peningkatan rasio $\mathrm{Si} / \mathrm{Al}$ sebesar 4,88 [9]. Peningkatan rasio $\mathrm{Si} / \mathrm{Al}$ diikuti dengan peningkatan kemampuan adsorpsi karena penurunan $\mathrm{Al}$ pada situs aktif Si-O-Al menyebabkan transformasi situs aktif menjadi Si-O-Si sehingga zeolit cenderung bersifat hidrofobik [10].

\section{Teori}

Adsorpsi adalah suatu proses yang terjadi ketika suatu fluida (cairan maupun gas) terikat kepada suatu padatan dan akhirnya membentuk suatu film (lapisan tipis) pada permukaan padatan tersebut. Ada 2 tipe adsorpsi, yaitu:

1. Adsorpsi fisis atau Van der Waals

Adsorpsi fisika diakibatkan gaya tarik menarik intermolekuler antara adsorbat dengan permukaan adsorben [11].

2. Adsorpsi kimia

Adsorpsi kimia menghasilkan pembentukan lapisan mono molekular adsorbat pada permukaan melalui gaya-gaya dari valensi sisa dari molekul-molekul pada permukaan [12].

Zeolit tersusun dari unit berulang terkecil berupa tetrahedra $\mathrm{SiO}_{4}$ dan $\mathrm{AlO}_{4}$. Ikatan antar tetrahedra terbentuk dengan pemakaian bersama satu atom oksigen oleh dua tetrahedra sehingga setiap tetrahedra akan berikatan dengan 4 tetrahedra lainnya. Polimer yang terbentuk adalah jaringan tetrahedra tiga dimensi berupa kristal-kristal yang didalamnya terdapat saluran-saluran pori dan rongga-rongga yang tersusun secara beraturan [5]. Agar zeolit dapat diaplikasikan sesuai fungsinya, maka diperlukan suatu proses aktivasi. Aktivasi secara fisis berupa pemanasan zeolit dengan tujuan untuk menguapkan air yang terperangkap dalam pori-pori kristal zeolit, sehingga luas permukaan pori-pori bertambah. Aktivasi secara kimiawi dilakukan dengan asam atau basa, yangbertujuan untuk membersihkan permukaan pori, membuang senyawa pengotor, dan mengatur kembali letak atom yang dapat dipertukarkan. sehingga zeolit lebih porous dan permukaan lebih aktif [5].

\section{Metodologi Penelitian \\ Proses Preparasi}

Zeolit alam diambil dari Kabupaten Sukabumi, Provinsi Jawa Barat. Proses preparasi dilakukan dengan cara zeolit digerus dan diayak menggunakan ayakan berukuran 50-70; 70-110; dan 110-120 mesh. Selanjutnya dicuci dengan aquadest dan dikeringkan dalam oven pada suhu $110^{\circ} \mathrm{C}$ selama 4 jam, kemudian dilakukan analisa SEM-EDS dilakukan pada profil permukaan zeolit sebelum diaktivasi.

\section{Proses Aktivasi}

Zeolit yang telah dipreparasi sebanyak $100 \mathrm{gr}$ kemudian diaktivasi dengan $300 \mathrm{ml} \mathrm{HCl} \mathrm{0,5} \mathrm{M} \mathrm{selama} 30$ menit dengan menggunakan waterbath shaker berkecepatan $200 \mathrm{rpm}$. Setelah itu suspensi ddiamkan selama 24 jam, lalu dicuci hingga $\mathrm{pH}$ netral $(7 \pm 6,8)$ dan dikeringkan dalam oven selama 5 jam dengan suhu $160^{\circ} \mathrm{C}$. Zeolit didinginkan dalam desikator selama 2 jam. dan dilakukan analisa SEM-EDS pada profil permukaan zeolit setelah diaktivasi.

\section{Proses Impregnasi}

Sebanyak $100 \mathrm{~g}$ Zeolit yang telah diaktivasi kemudian di impregnasi dengan $300 \mathrm{ml} \mathrm{MgCl} 2 \cdot 6 \mathrm{H}_{2} \mathrm{O} 2,5$ M selama 2 jam. Proses aktivasi menggunakan alat waterbath shaker dengan kecepatan $200 \mathrm{rpm}$. Setelah itu zeolit ddiamkan selama 24 jam, lalu dicuci hingga $\mathrm{pH}$ netral $(7 \pm 6,8)$, kemudian dikeringkan pada oven selama 5 jam dengan suhu $160^{\circ} \mathrm{C}$. Setelah itu zeolit didinginkan dalam desikator selama 2 jam. Selanjutnya dilakukan analisa SEM-EDS pada profil permukaan zeolit setelah dimpregnasi.

\section{Proses Penentuan Waktu Kontak Optimum}

Zeolit yang telah terimpregnasi dengan dosis $0,07 \%$ $\mathrm{m} / \mathrm{v}$ ditambahkan larutan amonia $25 \mathrm{mg} / \mathrm{L}$ sebanyak 100 $\mathrm{mL}$ dan diaduk dengan magnetic stirrer dengan kecepatan $150 \mathrm{rpm}$ selama 15 menit. Filtrat diambil dengan variasi waktu kontak $(0,5,10,15,20,25,30,35,40$ dan 45 menit), lalu disaring dengan kertas saring dan dilakukan analisa Spektrofotometer UV-Vis dengan panjang gelombang 640 $\mathrm{nm}$. 


\section{Proses Adsorpsi}

Zeolit yang telah diaktivasi dan diimpregnasi dengan variasi dosis adsorben $(0,01 \% ; 0,03 \%, 0,05 \%$; $0,07 \% ; 0,09 \% ; 0,11 \% ; 0,13 \% \mathrm{~m} / \mathrm{v}$ ) dimasukkan ke dalam beaker glass dan ditambahkan $100 \mathrm{ml}$ larutan amonia 25 $\mathrm{mg} / \mathrm{L}$. Diaduk dengan stirrer dengan kecepatan $150 \mathrm{rpm}$ selama 15 menit. Filtrat diambil dengan waktu kontak optimum yang telah didapatkan dan disaring menggunakan kertas saring serta dilakukan analisa Spektrofotometer UV-Vis dengan panjang gelombang 640 nm. Percobaan diulangi untuk perlakuan partikel adsorben (setelah aktivasi dan setelah impregnasi).

\section{Analisa Komposisi dan Kuantitas Kadar Amonia}

Analisa Scanning Electron Microscope-Energy Dispersive Spectroscopy (SEM-EDS) dengan spesifikasi EVO MA 10 merek ZEISS untuk melihat struktur morfologi dan mengetahui komposisi unsur dari zeolit sebelum aktivasi, setelah aktivasi, dan setelah diimpregnasi.

\section{Hasil}

Pemaparan Hasil Karakterisasi Scanning Electron Microscope-Energy Dispersive Spectroscopy (SEM-EDS) Profil Permukaan Zeolit

Hasil karakterisasi SEM-EDS profil permukaan zeolit dapat dilihat pada Gambar 1. Sebelum Aktivasi, Gambar 2. Setelah Aktivasi dan Gambar 3. Setelah Aktivasi dan Impregnasi dengan perbesaran 1500 kali, sedangkan hasil EDS dapat dilihat pada Tabel 1.

Gambar 1 menunjukkan hasil analisa SEM profil permukaan zeolit sebelum aktivasi. Pada gambar diatas, terlihat profil permukaan zeolit yang masih tertutupi oleh kotoran dan tidak terlihat adanya pori-pori yang aktif

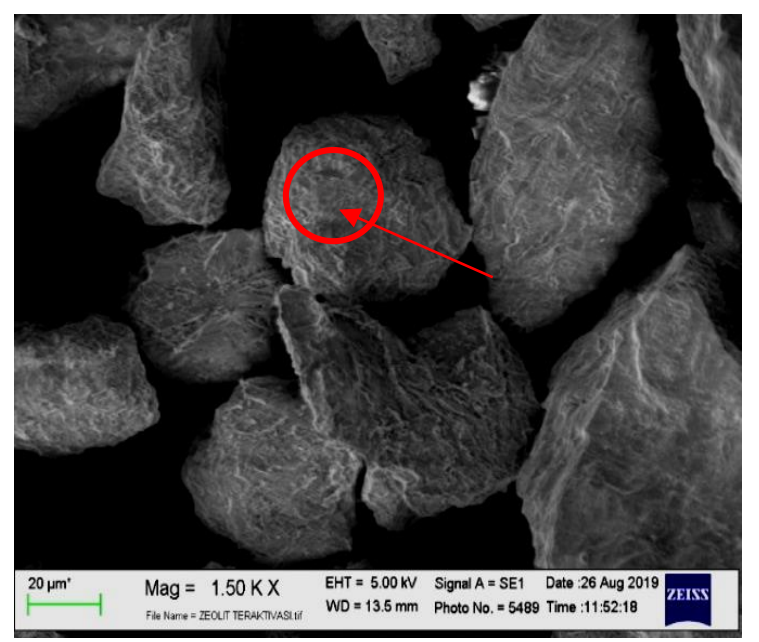

Gambar 1. Hasil analisa SEM profil permukaan zeolit sebelum aktivasi

Gambar 2 menunjukkan hasil analisa SEM profil permukaan zeolit setelah aktivasi. Pada Gambar 2 terlihat bahwa unsur-unsur pengotor yang sebelumnya menyelimuti permukaan zeolit sudah semakin berkurang. Proses aktivasi mampu mendorong keluar pengotor yang masih menutupi pori sehingga pori terbebas dari pengotor, maka dapat meningkatkan kualitas zeolit untuk digunakan sebagai adsorben dalam proses adsorpsi [10]. Semakin tinggi konsentrasi $\mathrm{HCl}$ yang ditambahkan maka semakin tinggi pula daya adsorbsinya.

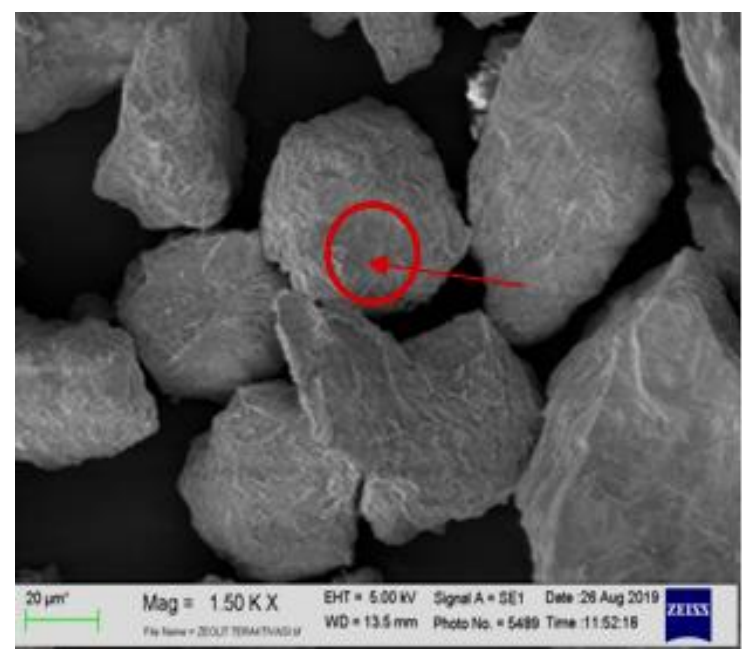

Gambar 2. Hasil analisa SEM profil permukaan zeolit setelah aktivasi

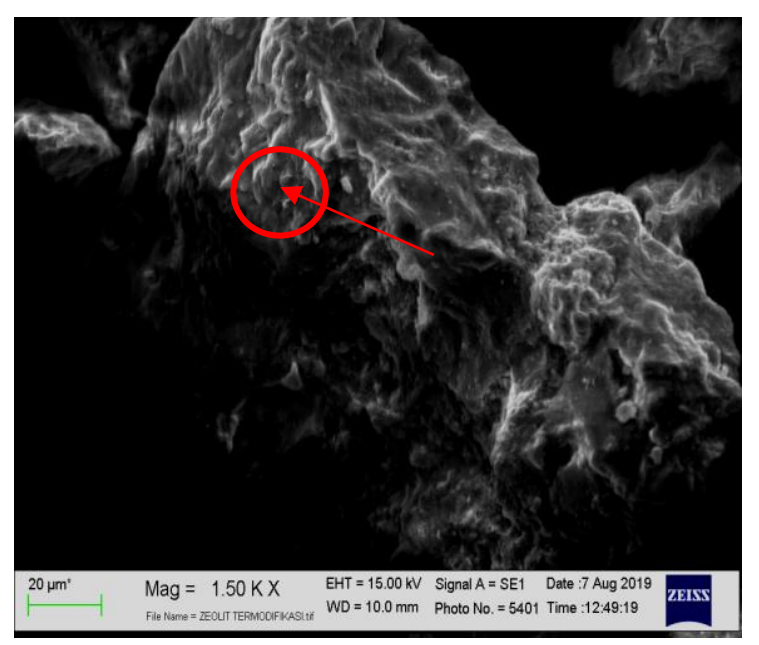

Gambar 3. Hasil analisa SEM profil permukaan zeolit setelah aktivasi dan impregnasi $\mathrm{Mg}^{2+}$

Gambar 3 profil permukaan zeolit setelah aktivasi $\mathrm{HCl}$ dan setelah impregnasi $\mathrm{Mg}^{2+}$. Pada Gambar 3, sangat terlihat jelas perbedaannya dengan Gambar 1 dan Gambar 2. Gambar 3 menunjukkan profil permukaan yang jauh lebih bersih dari pengotor serta partikel-partikel yang telah berkelompok sehingga membentuk sifat magnet dari magnesium.Partikel zeolit yang telah diimpregnasi dapat membentuk kelompok-kelompok (cluster) dengan sifat magnet dari magnesium sehingga partikel condong mengelompok. Hasil karakterisasi EDS profil permukaan zeolit sebelum aktivasi, setelah aktivasi dan setelah impregasi dapat kita lihat pada Tabel 1.

Proses aktivasi telah menghilangkan unsur K karena proses aktivasi menyebabkan keluarnya pengotor yang masih menutupi pori sehingga pori pori terbebas dari pengotor, sedangkan unsur $\mathrm{C}$ dan $\mathrm{Mg}^{2+}$ bertambah 
komposisinya saat dilakukan proses aktivasi karena kandugan unsur $\mathrm{C}$ dan $\mathrm{Mg}^{2+}$ sebenarnya ada pada zeolit sebelum diaktivasi, namun dalam jumlah yang sangat sedikit. Proses Impregnasi menambah kandungan unsur $\mathrm{Mg}^{2+}$ menjadi 2,23\% yang menunjukkan bahwa proses impregnasi dengan $\mathrm{MgCl}_{2}$ telah berhasil dilakukan walaupun massa $\mathrm{Mg}^{2+}$ yang menempel pada permukaan zeolit terbilang rendah. Penelitian tentang uji EDS untuk zeolit terimpregnasi dengan $\mathrm{MgCl}_{2}$ dimana menunjukkan bahwa terdapat pertambahan massa $\mathrm{Mg}^{2+}$ sebesar 4,73\% [7]. Juga terdapat unsur baru yang tidak terdapat saat sebelum impregnasi (setelah aktivasi) yaitu $\mathrm{Ca}, \mathrm{Na}$, Fe.Unsur $\mathrm{Na}$ dan $\mathrm{Fe}$ muncul dikarenakan menurunya unsur $\mathrm{O}$ setelah perlakuan aktivasi dan impregnasi sehingga berpeluang terbentuknya unsur lain seperti $\mathrm{Na}$ dan Fe.

Tabel 1. Hasil analisa EDS zeolit sebelum aktivasi, setelah aktivasi serta setelah aktivasi dan impregnasi

\begin{tabular}{|c|c|c|c|}
\hline \multirow{2}{*}{ Unsur } & \multicolumn{3}{|c|}{ Persentase (\% wt) } \\
\cline { 2 - 4 } & $\begin{array}{c}\text { Sebelum } \\
\text { Aktvasi }\end{array}$ & $\begin{array}{c}\text { Setelah } \\
\text { Aktivasi }\end{array}$ & $\begin{array}{c}\text { Setelah } \\
\text { Aktivasi } \\
\text { dan } \\
\text { Impregnasi }\end{array}$ \\
\hline $\mathrm{O}$ & 50,59 & 31,66 & 27,64 \\
\hline $\mathrm{Si}$ & 40,49 & 56,30 & 60,19 \\
\hline $\mathrm{Al}$ & 8,02 & 7,87 & 4,78 \\
\hline $\mathrm{C}$ & - & 2,95 & 0,72 \\
\hline $\mathrm{Ca}$ & - & - & 2,04 \\
\hline $\mathrm{K}$ & 0,78 & - & 2,60 \\
\hline $\mathrm{Fe}$ & - & - & 0,02 \\
\hline $\mathrm{Mg}$ & 0,22 & 0,78 & 2,23 \\
\hline $\mathrm{Na}$ & - & - & 0,32 \\
\hline
\end{tabular}

Perubahan unsur $\mathrm{Si}$ dan $\mathrm{Al}$ akan menyebabkan perubahan rasio $\mathrm{Si} / \mathrm{Al}$. Rasio $\mathrm{Si} / \mathrm{Al}$ sebelum aktivasi adalah 5,036, setelah aktivasi adalah 7,106 sedangkan setelah impregnasi adalah 12,592. Pelarutan silika akan menyebabkan perubahan struktur zeolit serta peningkatan rasio $\mathrm{Si} / \mathrm{Al}$ diikuti dengan peningkatan kemampuan adsorpsi karena penurunan Al menyebabkan zeolit cenderung bersifat hidrofobik[10].

\section{Penentuan Waktu Kontak Optimum}

Waktu kontak optimum adalah waktu minimum yang dibutuhkan adsorben (zeolit) pada saat proses penyerapan adsorbat (amonia) secara maksimum hingga mencapai keadaan jenuhnya. Variasi waktu kontak antara adsorbat dan adsorben hingga mencapai kesetimbangan adalah $0,5,10,15,20,25,30,35,40$, dan 45 menit dengan ukuran partikel adsorben 110-120 mesh. Grafik hubungan waktu kontak terhadap jumlah amonia yang terjerap dapat dilihat pada Gambar 4.

Waktu kontak antara adsorben dan adsorbat berbanding lurus dengan kapasitas adsorpsi. Kapasitas adsorpsi amonia dari waktu ke waktu meningkat dan menjadi lebih lambat hingga konstan pada waktu setimbang. Hal ini dikarenakan pada tahap awal jumlah permukaan sisi aktif adsorben yang tersedia lebih tinggi hingga akhirnya pada waktu setimbang zeolit sudah jenuh sehingga tidak mampu lagi mengadsorpsi ammonia.

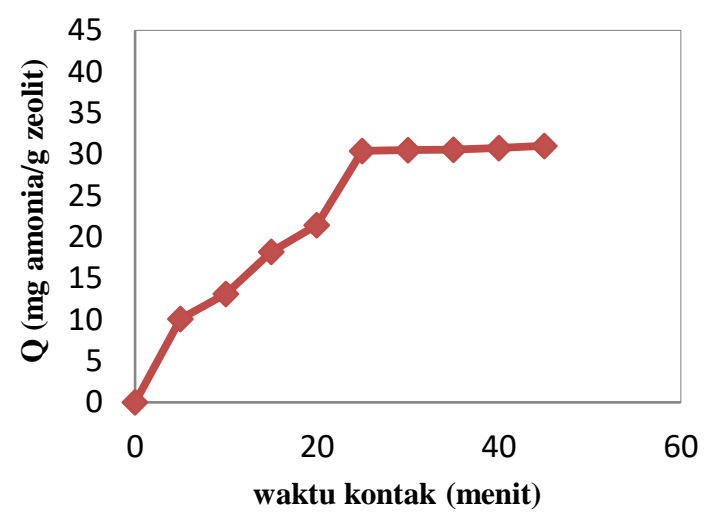

Gambar 4. Grafik hubungan lama waktu kontak (menit) terhadap kapasitas adsorpsi $(\mathrm{mg} / \mathrm{g})$ zeolit teraktivasi $\mathrm{HCl}$ dan terimpregnasi $\mathrm{Mg}$

Waktu kontak optimum penjerapan amonia dengan dosis adsorben zeolit $0,07 \%$ dan ukuran partikel adsorben 110-120 mesh adalah 25 menit dengan kapasitas adsorpsi $30,441 \mathrm{mg} / \mathrm{g}$ dan efisiensi penyerapan 85,2352\%. Pada waktu kontak awal kapasitas adsorpsi lebih besar karena ketersediaan jumlah pori aktif yang banyak dan laju perpindahan massa juga lebih besar. Semakin lama waktu kontak maka akan semakin banyak partikel-partikel zeolit yang bertumbukan dan berinteraksi dengan adsorbat sehingga penyerapannya meningkat seiring dengan menigkatnya waktu kontak hingga mencapai kesetimbangan.

\section{Pengaruh Dosis Adsorben Terhadap Efisiensi} Penjerapan pada Berbagai Perlakuan Adsorben

Grafik hubungan efisiensi penjerapan ion amonia dengan dosis adsorben pada berbagai perlakuan adsorben dapat dilihat pada Gambar .5.

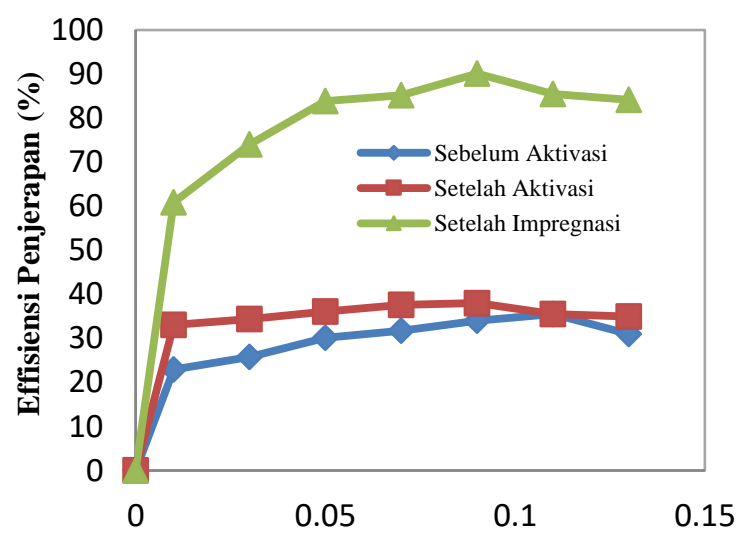

Dosis Adsorben (\% m/v)

Gambar 5. Hubungan efisiensi penjerapan ion amonia dengan dosis adsorben pada berbagai perlakuan adsorben

Proses aktivasi mampu mendorong keluar pengotor yang masih menutupi pori sehingga pori pori terbebas dari pengotor maka meningkatnya kualitas zeolit untuk 
digunakan sebagai adsorben dalam proses adsorpsi[10]. Sehingga kapasitas adsorpsi amonia dengan zeolit teraktivasi lebih baik hasilnya dibandingkan dengan menggunakan zeolit sebelum diaktivasi. Proses impregnasi dilakukan dengan menambahkan muatan logam $\mathrm{Mg}^{2+}$ pada permukaan adsorben zeolit. Zeolit terimpregnasi logam $\mathrm{Mg}^{2+}$ lebih maksimal penyerapannya dari pada zeolit teraktivasi untuk menyerap amonia. Oleh karena itu pada penelitian ini perlakuan impregnasi adsorben zeolit lebih banyak menjerap konsentrasi amoia daripada zeolit sebelum aktivasi dan setelah aktivasi.

Perlakuan adsorben zeolit sebelum aktivasi dan setelah aktivasi dengan $\mathrm{HCl}$ menampilkan gambar grafik yang tidak terlalu signifikan perbedaannya. Berbeda dengan perlakuan setelah impregnasi yang menunjukkan gambar grafik yang lebih signifikan dibandingkan perlakuaan sebelum dan setelah aktivasi $\mathrm{HCl}$. Hal ini dikarenakan pada proses impregnasi, larutan logam $\mathrm{Mg}^{2+}$ telah berikatan langsung dengan amonia yang merupakan adsorbat dari proses penjerapan diatas, sehingga amonia mengalami pertukaran komposisi ion menjadi $\mathrm{Mg}^{2+}$.

\section{Kesimpulan}

Adapun kesimpulan yang didapatkan yaitu struktur morfologi sesudah diaktivasi dengan $\mathrm{HCl}$ dan diimpregnasi dengan $\mathrm{Mg}^{2+}$ mempunyai pori-pori yang lebih banyak dari pada sebelum diaktivasi dan diimpregnasi karena zat-zat pengotor seperti $\mathrm{K}$ telah hilang. Waktu kontak optimum dalam penjerapan amonia adalah 25 menit. Efisiensi penjerapan tebaik yaitu pada ukuran partikel 110-120 mesh dengan perlakuan impregnasi $\mathrm{Mg}^{2+}$.

\section{Daftar Pustaka}

[1] C. Banon and T. E. Suharto, "Adsorpsi Amoniak Oleh Adsorben Zeolit Alam Yang Diaktivasi Dengan Larutan Amonium Nitrat," Univ. Stuttgart, vol. 4, no. 2, pp. 354-360, 2008.

[2] M. Azizah and M. Humairoh, "Analisis Kadar Amonia (Nh3) Dalam Air Di Sungai Cileungsi," J. Nusa Sylva, vol. 15, no. 1, pp. 47-54, 2015.

[3] T. H. Sungkowo, S. Elystia, and I. Andesgur, "Tanaman Typha Latifolia Dan Eceng Gondok Dengan," Jom Fteknik, vol. 2, pp. 1-8, 2015.

[4] S. A. Krisi, D. Dermawan, and U. P. Astuti, "Studi Pengaruh Variasi Volume Zeolite Terhadap Efisiensi Penurunan Kadar Ammonia ( NH 3 -N ) Limbah Cair Perusahaan Lubricant Refinery," no. 2581, pp. 113-117, 2013.

[5] M. Faisal, "Jurnal Kimia Sains dan Aplikasi Zeolit Alam Termodifikasi Logam Fe sebagai Adsorben Fosfat ( PO 43- ) pada Air Limbah," vol. 18, no. 3, pp. 91-95, 2015.

[6] W. S. Atikah, "Potensi Zeolit Alam Gunung Kidul Teraktivasi Sebagai Media Adsorben Pewarna Tekstil the Potentiality of Activated Natural Zeolite From Gunung Kidul As Adsorben To Textile Dyes," Arena Tekst., vol. 32, pp. 17-24, 2017, [Online]. Available: https://media.neliti.com/media/publications/217434 -karakterisasi-zeolit-alam-gunung-kidul-t.pdf.

[7] R. Ekawati, T. Taslimah, and P. Pardoyo, "Pengaruh Aktivasi Zeolit dengan $\mathrm{KMnO}_{4}, \mathrm{~K}_{2} \mathrm{~S}_{2} \mathrm{O}_{8}$ dan $\mathrm{H}_{2} \mathrm{SO}_{4}$ Terhadap Adsorpsifas Ion $\mathrm{Na}^{+}$dan $\mathrm{Mg}^{2+}$ Diujikan ada Air Tanah Karimunjawa Blok I," Jurnal Sains Dan Matematika, vol. 18, no. 4. pp. 150-157-157, 2010.

[8] M. Zabochnicka-Światek and K. Malińska, "Removal of ammonia by clinoptilolite," Glob. Nest $J$. , vol. 12, no. 3, pp. 256-261, 2010, doi: 10.30955/gnj.000724.

[9] J. B. Pavlović, J. K. Milenković, and N. Z. Rajić, "Modification of natural clinoptilolite for nitrate removal from aqueous media," J. Serbian Chem. Soc., vol. 79, no. 10, pp. 1309-1322, 2014, doi: 10.2298/JSC140116038P.

[10] D. Y. Lestari, "Kajian Modifikasi dan Karakterisasi Zeolit Alam dari Berbagai Negara," Pros. Semin. Nas. Kim. dan Pendidik. Kim. 2010, p. 6, 2010.

[11] Jasmal, Sulfikar, and Ramlawati, "Kapasitas adsorpsi arang aktif ijuk pohon aren (Arenga pinnata) terhadap Pb2+," J. Sainsmat, vol. 4, no. 1, pp. 5766, 2015

[12] S. Dur, "Zeolite Processing As Heavy Material," ZERO J. Sains, Mat. dan Terap., vol. 1, no. 1, pp. 33-45, 2017, doi: 10.30829/zero.v1i1.1457. 